\title{
Determination of Trace Level Lanthanides and Thorium by Inductively Coupled Plasma Atomic Emission Spectrometry in Different Types of Geological, Red Mud, and Coal Fly Ash Samples After Separation as Oxalates Using Calcium as Carrier
}

\author{
A. Premadas \\ Chemistry Laboratory, Southern Region \\ Atomic Minerals Directorate for Exploration and Research \\ Department of Atomic Energy, Nagarabhavi, Bangalore-560072, India
}

\begin{abstract}
Oxalate precipitation of lanthanides and thorium in acidic medium is a widely used group separation method at percentage to trace levels in different types of samples. In this report, a comparative study was made with the earlier reported conditions of trace level lanthanide separation as insoluble oxalates from a geological matrix at different $\mathrm{pH}$ values using calcium as carrier. The lanthanides and thorium are recovered quantitatively at trace levels as oxalates, using $300 \mathrm{mg}$ calcium as a carrier at $\mathrm{pH} 1$. The calcium is further removed by ammonium hydroxide precipitation in the presence of either stannic tin or ferric iron as the carrier. The combination of the two precipitative separations removed most of the matrix elements completely from the lan-
\end{abstract}

\section{INTRODUCTION}

The determination of lanthanides plays an important role in geology and geochemistry $(1,2)$. Their distribution pattern is widely used for petrogenetic studies; they are also used as catalysts, magnetic materials, and in the electronic industry (3-5). Increasingly, the production and use of certain lanthanides in the electronic industry leads to their release into the environment $(6,7)$.

\footnotetext{
*Corresponding author.

E-mail: apremadas@yaboo.co.in
}

thanides and thorium at trace levels in different types of geological samples, such as igneous rocks, soils, and refractory minerals like ilmenite, rutile, columbite-tantalite, garnet and silliminite, as well as in certain environmental and industrial waste materials

Accuracy of the method was checked by analyzing some Canadian Certified Reference Project Materials such as syenite samples SY-2 and SY-3, gabro sample MRG-1, soil samples SO-1, SO-2 and iron formation sample FeR-2, and also synthetic samples. The lanthanide and thorium values obtained for the reference materials is comparable with the recommended values, indicating that the method is fairly accurate and reproducibility is characterized by a relative standard deviation (RSD) of 1 to $6 \%(n=4)$.

This adversely affects plants, aquatic organisms, and can enter the human system. Therefore, the analysis of trace level lanthanides is of great significance in addition to its geochemical importance.

Different instrumental techniques, such as flame atomic absorption spectrometry (FAAS) (8), graphite furnace atomic absorption spectrometry (GFAAS) (9), inductively coupled plasma atomic emission spectrometry (ICP-AES) (10-12), and inductively coupled plasma mass spectrometry (ICP-MS)
(13-17), are used for the determination of lanthanides. Owing to its very good sensitivity, ICP-MS is widely used for the determination of lanthanides. However, in certain matrices it suffers from isobaric interferences, and a low process blank is often difficult to obtain. Due to the good sensitivity of ICPAES, most of the lanthanides can be determined at the earth crust concentration levels. However, due to the spectral interference (18) from certain major and minor matrix elements in geological materials, prior group separation is required.

Cation exchange chromatography (19-21) is also widely used for the group separation of lanthanides. This method has undergone many modifications, and each one has to be designed for certain types of geological samples. For that reason, there is a lack of simple, economical, and rapid separation methods that can be applied to different types geological samples, such as igneous rocks (acidic, basic, and ultra-basic), sedimentary rocks, soils, refractory minerals, industrial waste products (red mud: waste generated after the extraction of aluminum from bauxite ore using sodium hydroxide solution), and coal fly ash samples. This is due to the great variations in the sample matrix which requires different types of sample solution preparation procedures and selective separation of the lanthanides from different types of matrices. 
The commonly used cation exchange group separation procedure for lanthanides from other elements is rather slow. This means that a limited number of samples can be analyzed at a time; moreover, complete elution of both La and Ce from the column takes a longer time (tailing effects) using hydrochloric acid as eluent. With this method, thorium is not recovered, which is one of the important trace elements sought for the geochemical exploration of uranium.

The other separation procedures used for lanthanides are solvent extraction (22-24), fluoride precipitation (25), adsorption on activated carbon (26), and oxalate precipitation $(8,9,25,27,28)$. Even though fluoride precipitation provides a quantitative separation of the lanthanides and Th from major matrix elements, it is not a preferred method because of its corrosive nature and the handling problems of the hydrofluoric acid solution. Besides, the gelatinous nature of the precipitate means that filtration takes a longer time. It was also observed that the presence of alkali metals creates double salt precipitation of zirconium, niobium, and tantalum.

The simplest form of pre-concentration and sample matrix removal is co-precipitation. The oxalate precipitation of microgram levels of lanthanides and Th in the presence of calcium as a carrier removes the major matrix elements (such as $\mathrm{Fe}, \mathrm{Al}, \mathrm{Ti}, \mathrm{Mg}, \mathrm{Na}, \mathrm{K}, \mathrm{Mn}$, and phosphates) which are present in rock samples at milligram levels. However, the precipitation behavior of the lighter rare earth elements (LREEs) La to $\mathrm{Eu}$, and the heavier rare earth elements (HREEs) Ho to Lu, varies depending on the precipitation conditions (25). It was observed that their recoveries were also dependent on the quantity of calcium used as carrier. This procedure was used by Sen Gupta $(8,9)$, Iwasaki et al. (29) for the selective group separation of lanthanides from geological samples and using calcium as carrier. The quantity of carrier used by different workers ranges from $5 \mathrm{mg}$ to $150 \mathrm{mg}$ of calto different types of rock samples and some minerals, it was observed that the $\mathrm{pH}$ at the time of oxalate precipitation and the quantity of carrier used are important parameters, which have not been given significant importance earlier. This paper summarizes the conditions required for the quantitative separation of microgram levels of lanthanides from a wide variety of important materials in order to facilitate a spectral interference-free ICP-AES determination.
Roychowdhury et al. $(27,28)$, and cium. While applying the procedures

\section{Atomic Apectroscopy 1 Vol. 33(1), Jan./Feb. 2012}

\section{EXPERIMENTAL}

\section{Instrumentation}

All ICP-AES measurements were performed on an Integra model XM sequential spectrometer (GBC Scientific Equipment Company, Melbourne, Australia). The instrument was equipped with a rapid scanning monochromator (focal length, $750 \mathrm{~mm}$ ) with a ruled grating of 1800 grooves $\mathrm{mm}^{-1}$ and a Czerny-Turner mounting system. All measurements were carried out under vacuum conditions. Details of the instrumental parameters and other operating conditions are given in Table I. The analytical lines used are listed in Table II. All flame AAS measurements were made using a Spectra AA-20 atomic absorption spectrophotometer (Varian, Melbourne, Australia).

TABLE I

ICP-AES Operating Prameters

\begin{tabular}{|c|c|}
\hline RF Generator & cs, Model-2000 crystal-controlled \\
\hline Frequency & $40.68 \mathrm{MHz}$ \\
\hline Output power & $2.0 \mathrm{~kW}$ \\
\hline Induced power & $1.2 \mathrm{~kW}$ \\
\hline Reflected power & $<20 \mathrm{~W}$ \\
\hline \multicolumn{2}{|l|}{ Spectrometer } \\
\hline Mounting & Modified Czerny Turner \\
\hline Focal length & $750 \mathrm{~mm}$ \\
\hline Grating & 1800 grooves $\mathrm{mm}^{-1}$ \\
\hline Rules area & $52 \mathrm{~mm} \times 52 \mathrm{~mm}$ \\
\hline Dispersion & $0.74 \mathrm{~nm} \mathrm{~mm}^{-1}$ (first order) \\
\hline Wavelength range & $170-800 \mathrm{~nm}$ \\
\hline Wavelength repeatability & $\pm 0.002 \mathrm{~nm}$ \\
\hline Entrance slit & $20 \mu \mathrm{m}$ \\
\hline Exit slit & $20 \mu \mathrm{m}$ \\
\hline Photomultiplier & Dual, Hamamatsu R446 and R166 \\
\hline \multicolumn{2}{|l|}{ Operating Conditions } \\
\hline Argon gas flow rate & $10 \mathrm{~L} \mathrm{~min}^{-1}$ \\
\hline Auxilliary gas flow rate & $0.3 \mathrm{~L} \mathrm{~min}^{-1}$ \\
\hline Sample gas flow rate & $0.5 \mathrm{~L} \mathrm{~min}^{-1}$ \\
\hline Pump & Peristaltic 12 roller \\
\hline Nebulizer & Glass concentric \\
\hline Sample uptake & $1.7 \mathrm{~mL} \mathrm{~min}^{-1}$ \\
\hline Spray chamber & Cyclonic \\
\hline
\end{tabular}


The $\mathrm{pH}$ measurements were carried out using a digital $\mathrm{pH}$ meter, Model LI-122 (Elico Limited, Hyderabad, India).

\section{Reagents}

All reagents and chemicals used were of analytical or guaranteed reagent grade. Specpure ${ }^{\circledR}$ rare earth oxide (Johnson Matthey, U.K.) was used for the preparation of the standard solutions.

\section{Preparation of Standards}

A stock solution of $1000 \mu \mathrm{g} \mathrm{mL} \mathrm{m}^{-1}$ each was prepared from rare earth oxides by dissolving in hydrochloric acid solution and maintaining the acidity at $1 \mathrm{M} \mathrm{HCl}$.

TABLE II

Spectral Lines for Emission Measurement of Lanthanides and $\mathrm{Th}$, and the Background Correction Points Applied

\begin{tabular}{llll}
\hline Element & $\begin{array}{c}\text { Wave- } \\
\text { length } \\
(\mathrm{nm})\end{array}$ & \multicolumn{2}{c}{$\begin{array}{c}\text { Background } \\
\text { Correction }\end{array}$} \\
& $\mathrm{nm})$ & $\mathrm{R}(\mathrm{nm})$ \\
$\mathrm{La}$ & 333.749 & - & 0.020 \\
$\mathrm{Ce}$ & 418.660 & - & 0.020 \\
$\mathrm{Pr}$ & 422.293 & - & 0.022 \\
$\mathrm{Nd}$ & 430.358 & 0.019 & - \\
$\mathrm{Sm}$ & 442.434 & - & 0.019 \\
$\mathrm{Eu}$ & 381.967 & - & 0.021 \\
$\mathrm{Gd}$ & 342.247 & - & 0.020 \\
$\mathrm{~Tb}$ & 350.917 & 0.020 & - \\
$\mathrm{Dy}$ & 353.170 & 0.019 & - \\
$\mathrm{Ho}$ & 345.600 & - & 0.019 \\
$\mathrm{Er}$ & 349.910 & - & 0.020 \\
$\mathrm{Tm}$ & 346.220 & - & 0.021 \\
$\mathrm{Yb}$ & 328.937 & - & 0.018 \\
$\mathrm{Lu}$ & 261.542 & - & 0.009 \\
$\mathrm{Y}$ & 371.030 & - & 0.020 \\
$\mathrm{Th}$ & 353.959 & 0.020 & - \\
\hline $\mathrm{L}=\mathrm{Left}$ & $\mathrm{R}=\mathrm{Right}$ & \\
\hline & & & \\
\hline
\end{tabular}

Reference solutions were made up in the following combinations: $25 \mu \mathrm{g} \mathrm{mL}^{-1}$ each of Ce and $\mathrm{Nd}$; $20 \mu \mathrm{g} \mathrm{mL}^{-1}$ each of $\mathrm{La}, \mathrm{Pr}$, and Sm; $10 \mu \mathrm{g} \mathrm{mL}^{-1}$ each of Gd, Tb, Dy, and $\mathrm{Er} ; 5 \mu \mathrm{g} \mathrm{mL}^{-1}$ each of Ho, Tm, and Lu; $2 \mu \mathrm{g} \mathrm{mL}^{-1}$ each of $\mathrm{Yb}$ and $\mathrm{Y}$; and $4 \mu \mathrm{g} \mathrm{mL}^{-1}$ of Eu, prepared in $0.5 \mathrm{M}$ $\mathrm{HCl}$. For calibration, these stock solutions were further diluted to $5,10,25$, and 50 times while maintaining $0.5 \mathrm{M} \mathrm{HCl}$.

\section{Sample Dissolution}

Igneous Rocks, Soils, Sediments, Garnet, Silliminite, Red Mud, and Coal Fly Ash Samples

A mixture of nitric, perchloric, and hydrofluoric acid was used to decompose 1.000 to $2.000 \mathrm{~g} \mathrm{sam}$ ples as described earlier (24). The residue, if any, was fused with $0.5 \mathrm{~g}$ of a powdered mixture of $\mathrm{KHF}_{2}$ and $\mathrm{NaF}$ in a 3:1 ratio (hereafter referred to as flux; $2 \mathrm{~g}$ of flux was needed to fuse the residue obtained from $1 \mathrm{~g}$ of silliminite sample). The fluorides were removed by heating with $1 \mathrm{~mL}$ sulphuric acid ( $4 \mathrm{~mL}$ sulphuric acid for silliminite sample residue), then mixed with the mother solution.

Note: Samples containing organic matter (soil and stream sediments, and carbon in coal fly ash samples) were ignited in a muffle furnace at $850^{\circ} \mathrm{C}$.

\section{Ilmenite, Rutile, and Columbite- Tantalite}

A $0.500 \mathrm{~g}$ sample in a platinum crucible (30 mL capacity) was mixed with $2.5 \mathrm{~g}$ of flux. It was slowly heated on a low flame to melt the content, then to red-hot condition for about five minutes. While cooling, the melt was swirled to spread regularly over the inner sides of the wall. Then $8 \mathrm{~mL}$ of $50 \%$ sulphuric acid was added, slowly heated on a sand bath until disintegration of the fused mass, and further heated on a low flame burner to remove the fluorides. The content was taken into a $250-\mathrm{mL}$ capac- ity beaker containing $30 \mathrm{~mL}$ of $10 \%$ oxalic acid. It was then diluted to $100 \mathrm{~mL}$ and boiled until a clear solution was obtained; $1 \mathrm{~mL}$ hydrogen peroxide was also added in case of columbite-tantalite samples. This solution was used for the oxalate precipitation.

\section{Oxalate and Hydroxide Precipita- tion Separation of Traces of Lanthanides and Th}

To $100 \mathrm{~mL}$ of sample solution, $300 \mathrm{mg}$ of calcium and $30 \mathrm{~mL}$ of $10 \%$ oxalic acid solution were added (if oxalic acid was not added earlier), followed by the drop-wise addition of ammonia solution (1:1) until the appearance of white turbidity; then the $\mathrm{pH}$ was raised to 1 using a $\mathrm{pH}$ meter. The contents were boiled and digested on a boiling water bath for one hour. The precipitate was filtered through Whatman 540 filter paper and washed three times using $2 \%$ oxalic acid solution ( $\mathrm{pH}$ adjusted to $1 \mathrm{using}$ dilute hydrochloric acid). This solution was transferred into the same beaker and the filter paper rinsed with $5 \mathrm{~mL}$ each of concentrated nitric and hydrochloric acid. To this, $2 \mathrm{~mL}$ of perchloric acid was added and kept on a hot plate for evaporation until complete termination of perchloric acid fumes (evaporation and fuming were done inside the fume cupboard fitted with an efficient blower and scrubber system). Alternately, the residue can also be ignited in a platinum crucible at $650^{\circ} \mathrm{C}$ for one hour, subsequently dissolved in $5 \mathrm{~mL}$ hydrochloric acid and diluted to $100 \mathrm{~mL}$. Then $20 \mathrm{mg}$ of Sn(IV) solution was added as its chloride. The contents were warmed with $3 \mathrm{~g}$ of ammonium chloride, followed by the drop-wise addition of ammonia solution (1:1) to precipitate the hydroxides of $\mathrm{Sn}$, lanthanides, and Th ( $\mathrm{pH} \sim 9.5)$. This solution was filtered, washed four times using 5\% ammonia solution containing $1 \%$ ammonium nitrate, 
and finally rinsed once with distilled water. The residue was taken back into the same beaker using a fine jet of distilled water, followed by rinsing the paper with $10 \mathrm{~mL}$ of concentrated nitric acid; the volume was reduced to 3 to $4 \mathrm{~mL}$ on a boiling water bath to precipitate the tin as stannic acid. To this, $15 \mathrm{~mL}$ distilled water was added, and the contents digested for 5 minutes, cooled, and filtered through Whatman $\mathbf{5 4 0}$ filter paper containing $200 \mathrm{mg}$ ashless powder (cellulose filter aid, Whatman make). The residue was washed thoroughly with hot $0.8 \mathrm{M}$ nitric acid solution and diluted to $25 \mathrm{~mL}$ for ICP-AES determination of the lanthanides and Th.

Alternately, $10 \mathrm{mg}$ Fe(III) solution was added as its chloride, and the hydroxide precipitation and filtration were carried out as above. The precipitate was dissolved in $2.5 \mathrm{~mL}$ of hydrochloric acid and diluted to $25 \mathrm{~mL}$ for ICP-AES determination.

\section{RESULTS AND DISCUSSION}

According to the report by Zachman (30), the abundance (in $\mu \mathrm{g} \mathrm{g}^{-1}$ ) of lanthanides and Th in chondrites, earth crust, and North American shale concentrate (NASC) (as listed in Table III) are used for normalization of the lanthanide pattern. The concentrations of the lanthanides in one gram of these materials are $\sim 5.3,116$, and $193 \mu \mathrm{g}$, respectively. In a routine ICP-AES determination of lanthanides in rock samples, normally a one gram sample is taken for the selective separation of the lanthanides and the solution diluted to $25 \mathrm{~mL}$ with distilled water for sequential ICP-AES analysis or $10 \mathrm{~mL}$ for simultaneous ICPAES analysis. Using these dilution conditions, the concentration of $\mathrm{Pr}$, $\mathrm{Sm}, \mathrm{Tb}, \mathrm{Ho}$, and Tm was very low and resulted in very poor emission signals. In such cases, it is necessary to take a larger sample for the separation and determination. Taking $2 \mathrm{~g}$ or more of a sample for the ion exchange separation, the iron and aluminum levels in the lanthanides fraction increased. Moreover, the detailed study carried out by Iwasaki et al. (29) indicates that during the cation exchange separation of the lanthanides, the presence of higher quantities of iron and aluminum leads to poor recovery of certain lanthanides ( $\mathrm{Sm}, \mathrm{Eu}$, and Gd) due to their premature elution.

The solvent extraction procedures used by Weiss et al. (23), who used tri-n-octyl phosphine oxide, and by Srivastava et al. (24), who used a mixture of 2-ethylhexyl dihydrogen phosphate and bis-(2ethylhexyl) monohydrogen phosphate, have limitations. With a

TABLE III

Lanthanides and Thorium Abundances in Chondrites, Earth Crust, and North American Shales

\begin{tabular}{cccc}
\hline $\begin{array}{c}\text { Ele- } \\
\text { ment }\end{array}$ & $\begin{array}{c}\text { Chon- } \\
\text { drites } \\
\left(\mu \mathrm{g} \mathrm{g}^{-1}\right)\end{array}$ & $\begin{array}{c}\text { Earth } \\
\text { Crust } \\
\left(\mu \mathrm{g} \mathrm{g}^{-1}\right)\end{array}$ & $\begin{array}{c}\text { NASC } \\
\left(\mu \mathrm{g} \mathrm{g}^{-1}\right)\end{array}$ \\
\hline $\mathrm{Y}$ & 1.96 & 22.00 & 27.00 \\
$\mathrm{La}$ & 0.33 & 19.00 & 32.00 \\
$\mathrm{Ce}$ & 0.88 & 38.00 & 73.00 \\
$\mathrm{Pr}$ & 0.112 & 4.30 & 7.90 \\
$\mathrm{Nd}$ & 0.60 & 16.00 & 33.00 \\
$\mathrm{Sm}$ & 0.181 & 3.70 & 5.70 \\
$\mathrm{Eu}$ & 0.069 & 1.10 & 1.24 \\
$\mathrm{Gd}$ & 0.249 & 3.60 & 5.20 \\
$\mathrm{~Tb}$ & 0.047 & 0.64 & 0.85 \\
$\mathrm{Dy}$ & 0.325 & 3.70 & - \\
$\mathrm{Ho}$ & 0.070 & 0.82 & 1.04 \\
$\mathrm{Er}$ & 0.200 & 0.249 & 2.30 \\
$\mathrm{Tm}$ & 0.030 & 0.32 & 0.50 \\
$\mathrm{Yb}$ & 0.200 & 2.20 & 3.10 \\
$\mathrm{Lu}$ & 0.034 & 0.30 & 0.48 \\
$\mathrm{Th}$ & $2-4.44^{\mathrm{a}}$ & $11.5^{\mathrm{a}}$ & $10.1^{\mathrm{a}, \mathrm{b}}$ \\
\hline $\mathrm{aK}$
\end{tabular}

${ }^{\mathrm{a}}$ K. Rankama and T.G. Sahama, Eds. Geochemistry, The University of Chicago Press, Chicago, IL, USA (1950).

b Shales of Miami, FL, USA.

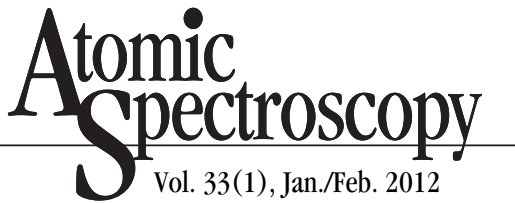

sample amount of about $1.5 \mathrm{~g}$ for separation of the lanthanides, it required a close $\mathrm{pH}$ adjustment of the sample solution without causing hydrolysis of titanium. Moreover, the above separation methods cannot be applied to samples containing (a) large quantities of titanium (ilmenite and rutile), (b) iron and aluminum (basic, ultra-basic rocks, and red mud samples), (c) in the presence of excessive salts introduced by way of fusion of the refractory minerals (ilmenite, rutile, columbite-tantalite, garnet. and silliminite), and (d) in the presence of complexing agents such as oxalic acid used to prevent hydrolysis of the elements ( $\mathrm{Ti}, \mathrm{Nb}$, and $\mathrm{Ta}$ ).

The present study concentrates on three aspects: (a) a re-investigation into the quantitative co-precipitation conditions for trace amounts of lanthanides and Th as oxalates using calcium as carrier, (b) studying the effects of calcium on the emission signal of low trace level lanthanides (likely to be present in a 25-mL solution prepared from one gram of sample) during ICP-AES determination, (c) application of the proposed separation method to different types of igneous rocks and refractory minerals (ilmenite, rutile, columbite-tantalite, garnet, and silliminite), environmental samples (soils), and industrial waste materials (red mud and coal fly ash).

\section{Oxalate Precipitation of Lanthanides and Th}

Figure 1 shows the effect of $\mathrm{pH}$ ( 1 to 4 ) on oxalate precipitation of some lanthanides using $50 \mathrm{mg}$ of calcium as carrier for a synthetic granite rock sample solution containing microgram amounts of lanthanides. The results show that at pH 1 all of the lanthanides were recovered quantitatively (more than $97 \%$ ). At the $\mathrm{pH}$ of around 2.3, the recovery was about $95 \%$ for holmium; for other HREEs it became less, and was less than 90\% 
for lutetium. At $\mathrm{pH} \sim 3.3$, an incomplete recovery was noted also for the LREEs; lanthanum recovery was around $80 \%$ and lutetium was about $60 \%$. The loss further increased at pH 4.2 and above. The above data indicate that (a) $\mathrm{pH}$ adjustments are very critical for the complete recovery of lanthanides, (b) preferably, the $\mathrm{pH}$ should be adjusted using a $\mathrm{pH}$ meter, and (c) the precipitation $\mathrm{pH}$ should be between 0.9 to 1.1 for the complete recovery of all lanthanides. Under these conditions the recovery of Th was also quantitative.

It was also observed that if the solution $\mathrm{pH}$ increases beyond 3 (while adjusting the $\mathrm{pH}$ with dilute ammonia solution) and if subsequently the solution is brought below 1 by the addition of dilute hydrochloric acid, lanthanide loss was noted. This indicates that once the lanthanides are converted into a soluble oxalate form at a $\mathrm{pH}$ greater than 3 , re-conversion into the insoluble oxalate form is not completed by decreasing the $\mathrm{pH}$ to 1 . By increasing the quantity of the carrier (calcium) from 50 to $200 \mathrm{mg}$, recovery of the lanthanides also increases, and almost complete recovery is obtained at $\mathrm{pH} 2$ or less. More oxalic acid was needed to complex the presence of higher amounts of iron and the hydrolysable elements such as titanium, niobium, and tantalum. Therefore, the $\mathrm{pH}$, quantity of calcium added as carrier, and quantity of oxalic acid are important factors in obtaining quantitative recovery of lanthanides and Th in different types of geological materials.

Iwasaki et al. (29) reported the co-precipitation of trace level lanthanides as oxalates when using $2 \mathrm{~g}$ of oxalic acid and calcium as carrier (calcium added is not reported), and adjusting the $\mathrm{pH}$ of the rock sample solution to between 3.5 and 4 at the time of precipitation. Subsequently, calcium was removed using the cation exchange separation method, and the lanthanides were determined by ICP-AES. Using the above conditions, the oxalate precipitation was carried out in an intermediate basic-type rock sample (Jaduguda uranium ore-grade sample from India) and the lanthanide results were compared with the ion exchange (IE) procedure (21). The results listed in Table IV clearly indicate a clear loss of lanthanides when the oxalate precipitation separation was carried out at a pH of approximately 3 .

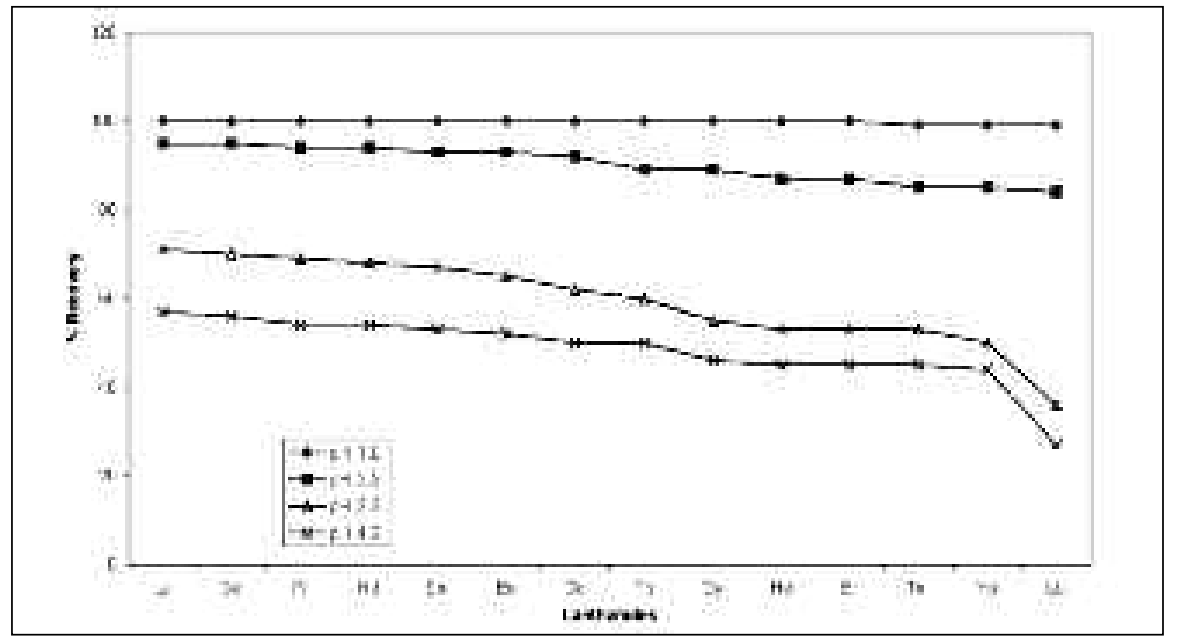

Fig. 1. Effect of $p H$ on the recovery of trace amounts of REEs as oxalates from a granite matrix using $50 \mathrm{mg} \mathrm{Ca}$ as carrier.
Roychowdhury et al. (27) also used calcium oxalate co-precipitative separation of lanthanides with $50 \mathrm{mg}$ of calcium as carrier to separate the lanthanides from a onegram sample. In their latter report (28) they used only $5 \mathrm{mg}$ of calcium as carrier for the recovery of lanthanides from bauxite samples. Although they did not mention the $\mathrm{pH}$ of the precipitation conditions in their first report (27), in the second report (28) the $\mathrm{pH}$ was adjusted to around 2 . It was observed that at $\mathrm{pH} 1$ no significant precipitate of calcium oxalate was noticed using only $5 \mathrm{mg}$ calcium as carrier (total volume $100 \mathrm{~mL}$ ). And

\section{TABLE IV}

Recovery Studies of Lanthanides (in $\mu$ g) from a Rock Sample Solution With Oxalate

Co-precipitation Using $50 \mathrm{mg}$ Ca as Carrier at Different $\mathbf{p H}$

\begin{tabular}{|c|c|c|c|c|}
\hline $\begin{array}{l}\text { Ele - } \\
\text { ment }\end{array}$ & $\begin{array}{l}\text { IE Sepa- } \\
\text { ration }^{\mathrm{a}}\end{array}$ & $\begin{array}{r}\mathrm{Co}- \\
\mathrm{pH} \sim 1\end{array}$ & $\begin{array}{l}\text { Oxalate } \\
\text { precipi } \\
\text { pH 3 }\end{array}$ & $\begin{array}{l}\text { tation } \\
\mathrm{pH} \sim 4\end{array}$ \\
\hline $\mathrm{La}$ & 285 & 295 & 211 & 170 \\
\hline $\mathrm{Ce}$ & 545 & 560 & 400 & 315 \\
\hline $\mathrm{Pr}$ & 57 & 59 & 39 & 32 \\
\hline $\mathrm{Nd}$ & 220 & 216 & 152 & 125 \\
\hline $\mathrm{Sm}$ & 36 & 37 & 26 & 20 \\
\hline $\mathrm{Eu}$ & 4.4 & 4.6 & 3.1 & 2.5 \\
\hline Gd & 31 & 32 & 20 & 16 \\
\hline $\mathrm{Tb}$ & 3.9 & 4.0 & 2.4 & 2.1 \\
\hline Dy & 22.9 & 23.5 & 12.9 & 10.9 \\
\hline Ho & 3.9 & 4.0 & 2.1 & 1.7 \\
\hline $\mathrm{Er}$ & 12.0 & 12.5 & 6.7 & 5.8 \\
\hline $\mathrm{Tm}$ & 1.6 & 1.6 & 0.9 & 0.8 \\
\hline $\mathrm{Yb}$ & 10.6 & 10.7 & 5.3 & 4.7 \\
\hline $\mathrm{Lu}$ & 0.96 & 0.98 & 0.36 & 0.26 \\
\hline $\mathrm{Y}$ & 86 & 87 & 50 & 45 \\
\hline
\end{tabular}


at $\mathrm{pH} 2$, using $10 \mathrm{mg}$ of calcium, the loss was around $20 \%$ for holmium and around 35\% for lutetium. This type of loss was negligible when the precipitation was carried out at pH 1 using $50 \mathrm{mg}$ or more of calcium. It was also observed that in the presence of major quantities of iron, aluminum, titanium, niobium, and tantalum in the sample, the precipitation behavior of the lanthanide oxalates further changes resulting in incomplete recovery of the lanthanides even with $50 \mathrm{mg}$ of calcium as carrier. However, further detailed studies in this regard indicate that using $200 \mathrm{mg}$ or more of calcium as carrier at $\mathrm{pH} \mathrm{1,} \mathrm{complete} \mathrm{recovery} \mathrm{of}$ trace level lanthanides and Th can be achieved, irrespective of the concentration of the matrix elements present in the sample.

\section{Effect of Calcium on Emission Signal of Lanthanides}

Thompson et al. (31) studied the effects of calcium ( 0 to $10 \mathrm{mg} \mathrm{mL}^{-1}$ ) on the emission signal of $5 \mu \mathrm{g} \mathrm{mL} \mathrm{m}^{-1}$ each of $\mathrm{Ba}, \mathrm{Cd}, \mathrm{Cr}, \mathrm{Cu}, \mathrm{La}, \mathrm{Li}, \mathrm{Ni}, \mathrm{Pb}$, $\mathrm{Rb}, \mathrm{Sr}, \mathrm{V}$, and $\mathrm{Zn}$, and $0.5 \mu \mathrm{g} \mathrm{mL}^{-1}$ each of $\mathrm{Be}, \mathrm{Cd}$, and Mo using the emission line wavelengths ranging from $220.35 \mathrm{~nm}$ to $780.02 \mathrm{~nm}$, covering the excitation potential of $1.59 \mathrm{eV}$ to $7.37 \mathrm{eV}$. The commonly used forward power of $1250 \mathrm{~W}$ was used for the study. This report shows that the presence of calcium matrix suppresses the emission signal. To overcome this effect, the use of an Interactive Matrix Matching (IMM) or the Parameter-related Internal Standard Method (PRISM) was suggested. They also observed that matrix effects were due to variations in the efficiency of excitation processes in the plasma rather than the effect of solution viscosity on the nebulizer efficiency.

Romero et al. (32) and Brenner et al. (33) studied the effect of easily ionizable elements (EIEs) like sodium on the emission signal of certain trace elements. They observed a suppression of the emission signal in the presence of EIEs. This suppression was attributed to a change in the plasma properties by the matrix elements. Excess of nitric acid in the sample solution is also known to cause the suppression of the emission signal $(34,35)$; therefore, it is necessary to keep the acidity of nitric acid at less than $1 \mathrm{M}$.

In the present study, the matrix effects of calcium ( 0.5 to $2 \mathrm{mg} \mathrm{mL}^{-1}$ ) on the lanthanide emission lines were studied using the concentration obtained by the 10-fold dilution of the reference stock solutions mentioned in the experimental section with a forward power of $1200 \mathrm{~W}$. The solution was aspirated into the plasma with a concentric nebulizer, equipped with a 12-roller peristaltic pump, to avoid any changes in sample nebulization. It was found that in the presence of up to $0.5 \mathrm{mg} \mathrm{mL}^{-1}$ of calcium, no significant change in the emission signal was observed. But in the case of a matrix containing $1 \mathrm{mg} \mathrm{mL}^{-1}$ of calcium, the emission signal was suppressed and ranged from 5 to $8 \%$.

Studies were also conducted by varying the forward power from 800 to $1500 \mathrm{~W}$. It shows that in the presence of $1 \mathrm{mg} \mathrm{mL}^{-1} \mathrm{Ca}$, the suppression of the lanthanide emission signal was higher (8 to $10 \%$ ) while using $800 \mathrm{~W}$ forward power. Although the suppression is reduced (3 to $5 \%$ ) at $1500 \mathrm{~W}$ forward power, it cannot be eliminated. The results obtained when using $1250 \mathrm{~W}$ forward power show similar behavior as reported by Thompson et al. (31). On the basis of the above observations it was necessary to separate the major amounts of calcium from the lanthanide fraction to ensure the accurate ICP-AES determination of the lanthanides and Th.

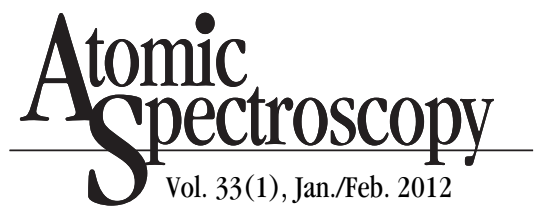

\section{Hydroxide Precipitation of Lanthanides and Th}

The hydroxide precipitation of lanthanides is also $\mathrm{pH}$-dependent. The precipitation behavior of LREEs is slightly different from HREEs because the basicity decreases from lanthanum to lutetium. In order to estimate the quantity of carrier Sn(IV) or Fe(III) needed to quantitatively precipitate the trace amounts of lanthanides and Th, studies were conducted with varying amounts of the carriers. It was observed that $10 \mathrm{mg}$ of either Sn(IV) or Fe(III) is sufficient for the complete recovery of the lanthanides (Table V). The advantage of Sn(IV) over Fe(III) is that after co-precipitation, treatment of the Sn(IV) hydroxide precipitate with nitric acid converts it into an insoluble stannic acid (36), whereas the lanthanides and Th remain in solution. Since filtration was carried out under acidic conditions (0.8 $\left.\mathrm{M} \mathrm{HNO}_{3}\right)$, no significant occlusion of the lanthanides was observed. The calcium and tin found in the lanthanide fraction was less than $100 \mu \mathrm{g} \mathrm{mL}^{-1}$ and $10 \mu \mathrm{g} \mathrm{mL}^{-1}$, respectively. At this level, no interference due either to calcium or tin was noticed on the emission signal of the lanthanides and Th.

TABLE V

Hydroxide Precipitative Separation of $\mu \mathrm{g}$ Amounts of Certain Lanthanides and Th Using $10 \mathrm{mg}$ Fe(III) or $10 \mathrm{mg}$ Sn(IV) as Carrier

\begin{tabular}{cccc}
\hline \multirow{2}{*}{$\begin{array}{c}\text { Ele- } \\
\text { ment }\end{array}$} & $\begin{array}{c}\text { Quantity } \\
\text { taken } \\
(\mu \mathrm{g})\end{array}$ & \multicolumn{2}{c}{$\begin{array}{c}\text { Quantity Recovered } \\
\text { along }\end{array}$} \\
& Fe(II) & Sn(IV) \\
\hline $\mathrm{La}$ & 50.0 & 48.5 & 50.2 \\
$\mathrm{Ce}$ & 55.0 & 54.0 & 55.0 \\
$\mathrm{Eu}$ & 8.5 & 8.3 & 8.5 \\
$\mathrm{Dy}$ & 25.0 & 24.5 & 24.8 \\
$\mathrm{Lu}$ & 10 & 9.9 & 9.9 \\
$\mathrm{Yb}$ & 4.5 & 4.3 & 4.5 \\
$\mathrm{Y}$ & 25.0 & 24.5 & 24.8 \\
$\mathrm{Th}$ & 50 & 48 & 49 \\
\end{tabular}




\section{Validation of Analytical Method}

In order to check the accuracy, the proposed method was applied to six samples obtained from the Canadian Certified Reference Materials Project (CCRMP): SY-2 and SY-3 Syenite Rock samples, MRG-1 Gabro sample, SO-2 and SO-4 Soil samples, and FeR-2 Iron Formation sample. The analytical results for the reference materials are listed in Tables VI and VII. The percentage of relative standard deviation (RSD) obtained for each lanthanide and Th for the SY-2 Syenite sample is indicated in parentheses. The results show that the method has fairly good accuracy (>95\% recovery) and reproducibility.

\section{Applications to Different Samples}

Bauxite, Red Mud, and Coal Fly Ash

Table VIII lists the results obtained for bauxite and red mud samples (bauxite ore was obtained from Belgaum, Karnataka, India; red mud sample was generated in the laboratory by the extraction of aluminum from the ore using sodium hydroxide solution), and a standard reference material SRM 1633a Coal Fly Ash (obtained from the National Institute of Standards and Technology, Gaithersburg, MD, USA). The values obtained by the proposed method agree well with the cation exchange separation method carried out after oxalate precipitation ( $\mathrm{pH}$ 1) separation of the lanthanides and Th. The results are in fairly good agreement, and the reproducibility of the results is also good.

\section{Garnet and Silliminite Samples \\ Garnet and silliminite samples} are refractory aluminosilicates and do not decompose completely by acid digestion treatment. The residue thus obtained was fused with a mixture of sodium fluoride and potassium bi-fluoride which adds a large amount of salt to the solution. The advantage of the proposed separation procedure is that it can be applied directly even to solutions having a high salt content. The recovery of the lanthanides and Th by this method was compared with the ion exchange separation method (21). The results obtained for these samples (beach sand from the Chavara Coast, Kol-
TABLE VI

Recovery Studies of Lanthanides and Th by Proposed Method Using CCRMP SRMs SY-2 and SY-3 Syenite Rock Samples and MRG-1 Gabro Sample

\begin{tabular}{lllllll}
\hline $\begin{array}{l}\text { Ele- } \\
\text { ment }\end{array}$ & \multicolumn{2}{c}{ Found } & $\begin{array}{c}\text { Sepor- } \\
\text { ted }^{\mathrm{a}}\end{array}$ & Found & $\begin{array}{c}c \\
\text { Repor- } \\
\text { ted }^{\mathrm{a}}\end{array}$ & $\begin{array}{c}\text { Found } \\
\text { ted }\end{array}$ \\
\hline $\mathrm{La}$ & $73(2.1)$ & 75 & 1324 & 1340 & 10.5 & 9.8 \\
$\mathrm{Ce}$ & $170(2.3)$ & 175 & 2300 & 2230 & 27 & 26 \\
$\mathrm{Pr}$ & $17.5(4.7)$ & 18.8 & 210 & 223 & 3.5 & 3.4 \\
$\mathrm{Nd}$ & $71(3.5)$ & 73 & 708 & 670 & 18 & 19.2 \\
$\mathrm{Sm}$ & $14.5(4.2)$ & 16.1 & 107 & 109 & 4.4 & 4.5 \\
$\mathrm{Eu}$ & $2.30(2.1)$ & 2.42 & 18 & 17 & 1.37 & 1.39 \\
$\mathrm{Gd}$ & $16.4(3.7)$ & 17 & 115 & 105 & 3.9 & 4 \\
$\mathrm{~Tb}$ & $3.0(5.7)$ & 2.5 & 18.9 & 18 & $<1$ & 0.5 \\
$\mathrm{Dy}$ & $17.7(3.2)$ & 18 & 115 & 118 & 2.9 & 2.9 \\
$\mathrm{Ho}$ & $4.2(3.8)$ & 3.8 & 26.5 & 29.5 & 0.5 & 0.49 \\
$\mathrm{Er}$ & $13.1(5.6)$ & 12.4 & 70 & 68 & 1.1 & 1.12 \\
$\mathrm{Tm}$ & $2.0(6.0)$ & 2.1 & 11.0 & 11.6 & $<0.5$ & 0.11 \\
$\mathrm{Yb}$ & $17.3(2.7)$ & 17 & 59 & 62 & 0.8 & 0.6 \\
$\mathrm{Lu}$ & $2.8(2.6)$ & 2.7 & 7.2 & 7.9 & $<0.2$ & 0.12 \\
$\mathrm{Y}$ & $123(2.1)$ & 128 & 710 & 718 & 13.2 & 14 \\
$\mathrm{Th}$ & $369(4.0)$ & 380 & 1015 & 990 & $<10$ & 0.93 \\
\hline
\end{tabular}

a Reported Govindraju, Geostand. Newsl., Special Issue, Vol. XVIII (1994).

Values are in $\mu \mathrm{g} \mathrm{g}^{-1}$.

Values in parentheses are \%RSD.
TABLE VII

Recovery Studies of Lanthanides and Th by Proposed Method Using CCRMP SRMs SO-2 and SO-4 Soil Samples and FeR-2 Iron Formation Sample \begin{tabular}{llll}
\hline Ele- & SO-2 & SO-4 & FeR-2
\end{tabular} ment Found Repor- Found Repor- Found Repor\begin{tabular}{lllllll} 
& & ted $^{\text {a }}$ & & ted $^{\text {a }}$ & & ted $^{\text {a }}$ \\
\hline $\mathrm{La}$ & 43 & 46.5 & 27 & 28.2 & 10 & 12
\end{tabular} $\begin{array}{lllllll}\text { Ce } & 110 & 112 & 55 & 54 & 23 & 25\end{array}$ $\begin{array}{lllllll}\operatorname{Pr} & 12.5 & 14.3 & 6.8 & 7.2 & <3 & 3\end{array}$ $\begin{array}{lllllll}\text { Nd } & 55 & 57 & 24 & 25 & 11 & 12\end{array}$ $\begin{array}{lllllll}\text { Sm } & 11 & 11.8 & 4.2 & 4.7 & <3 & 2.5\end{array}$ $\begin{array}{lllllll}\text { Eu } & 3.25 & 3.15 & 0.89 & 0.97 & 1.2 & 1.25\end{array}$ $\begin{array}{lllllll}\text { Gd } & 11 & 11.1 & 3.2 & 3.9 & <3 & 2\end{array}$ $\begin{array}{lllllll}\text { Tb } & 1.5 & 1.62 & <1 & 0.61 & <1 & 0.32\end{array}$ $\begin{array}{lllllll}\text { Dy } & 8.5 & 8.8 & 3.3 & 3.5 & 1.9 & 2\end{array}$ $\begin{array}{lllllll}\text { Ho } & 1.5 & 1.7 & 0.6 & 0.8 & 0.5 & 0.6\end{array}$ $\begin{array}{lllllll}\text { Er } & 4.0 & 4.2 & 2 & 2 & 1.6 & 1.5\end{array}$ $\begin{array}{lllllll}\mathrm{Tm} & 0.5 & 0.54 & <0.5 & 0.35 & <0.5 & 0.2\end{array}$ $\mathrm{Yb} \quad 3.6 \quad 3.5$ Lu $\quad 0.4 \quad 0.46$ $\begin{array}{llll}2.0 & 2.1 & 1.2 & 1.25\end{array}$ $\begin{array}{llll}0.3 & 0.37 & 0.2 & 0.2\end{array}$ $\begin{array}{lllllll}\mathrm{Y} & 39 & 40 & 21 & 22 & 15 & 16\end{array}$

$\begin{array}{lllllll}\text { Th } & <10 & 3.8 & <10 & 8.6 & <10 & 2.4\end{array}$

a Reported Govindraju, Geostand. Newsl., Special Issue, Vol. XVIII (1994).

Values are in $\mu \mathrm{g} \mathrm{g}^{-1}$. 
lam, Kerala, India) are listed in Table IX, along with the major chemical composition of the minerals. It shows close agreement with the values obtained by the IE method of separation. The \%RSD obtained for the garnet samples varied from 2.1 to 5.1 .

\section{Natural Ilmenite and Rutile, IGS-33 Columbite and IGS-34 Tantalite Samples}

A cation exchange separation method of lanthanides from ilmenite, rutile, and columbitetantalite performed in our laboratory was published earlier (37). An acid hydrolysis method for this type of analysis is suggested by Satyanarayana (38) for the separation and ICP-AES determination of lanthanides in columbite-tantalite minerals. However, with this later method, the separated lanthanide fraction contains major portions of certain major matrix elements (titanium, iron, and manganese) present in columbite-tantalite samples. The high amounts of these matrix elements are likely to cause spectral interference. In the absence of reference materials with certified values for lanthanides and Th in these types of materials, the accuracy of the proposed method was verified by applying the method on synthetic samples prepared in our laboratory (Table X). High purity oxides were mixed with a composition similar to the natural ilmenite, rutile, and columbite-tantalite samples, spiked with trace amounts of

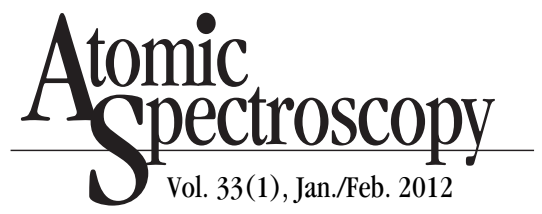

lanthanides and $\mathrm{Th}$. The recovery results of the lanthanides and Th in microgram $(\mu \mathrm{g})$ amounts are listed in Table $\mathrm{X}$ and indicate fairly good recovery values (>95\%).

The proposed separation procedure was also carried out using natural ilmenite and rutile minerals separated from other heavy minerals, such as monazite, magnetite, garnet, and silliminite (obtained from the beach sand of Chavara, Kollam district, Kerala, India), and certified reference materials IGS-33 Columbite and IGS-34 Tantalite (obtained from the Geochemistry and Petrology Division, Institute of Geological Sciences London, U.K). The results were compared with the ion exchange separation (37)
TABLE VIII

Comparative Results (in $\mu \mathrm{g} \mathrm{g}^{-1}$ ) of Recovery of Lanthanides and Th in Natural Bauxite and Red Mud, and SRM 1633a Coal Fly Ash Samples Using the Proposed Method (P) and the Cation Ion Exchange Separation Method (IE)

\begin{tabular}{lllllll}
\hline Element & \multicolumn{2}{c}{ Bauxite } & \multicolumn{3}{c}{ Red Mud } & \multicolumn{2}{c}{ SRM 1633a Coal } \\
& P & IE & P & IE & P & IE \\
\hline $\mathrm{La}$ & 57 & 55 & 70 & 72 & 67 & 70 \\
$\mathrm{Ce}$ & 115 & 112 & 210 & 205 & 175 & 174 \\
$\mathrm{Pr}$ & 8.5 & 8.1 & 13 & 12 & 15 & 15 \\
$\mathrm{Nd}$ & 34 & 33 & 30 & 31 & 72 & 73 \\
$\mathrm{Sm}$ & 5.0 & 5.0 & 6.9 & 6.9 & 13 & 14 \\
$\mathrm{Eu}$ & 0.97 & 0.92 & 2.1 & 2.1 & 3.8 & 3.9 \\
$\mathrm{Gd}$ & 3.6 & 3.7 & 6.0 & 6.2 & 22 & 23 \\
$\mathrm{~Tb}$ & $<1$ & $<1$ & $<1$ & $<1$ & $<1$ & $<1$ \\
$\mathrm{Dy}$ & 2.9 & 2.9 & 3.7 & 3.8 & 13 & 12 \\
$\mathrm{Ho}$ & 0.6 & 0.6 & 1.5 & 1.6 & 2.5 & 2.4 \\
$\mathrm{Er}$ & 1.9 & 1.8 & 2.7 & 2.8 & 5.7 & 5.6 \\
$\mathrm{Tm}$ & $<0.5$ & $<0.5$ & 0.5 & 0.5 & 0.8 & 0.9 \\
$\mathrm{Yb}$ & 2.0 & 2.0 & 1.9 & 2.0 & 7.7 & 7.9 \\
$\mathrm{Lu}$ & 0.2 & 0.2 & 0.5 & 0.5 & 0.8 & 0.8 \\
$\mathrm{Y}$ & 12 & 13 & 12 & 11 & 87 & 85 \\
$\mathrm{Th}$ & 25 & 27 & 28 & 30 & 24 & 25 \\
\hline
\end{tabular}

${ }^{a}$ Thorium was determined by ICP-AES after standard anion exchange separation in $\sim 8 M$ nitric acid medium (Ref. 39). All values are in $\mu \mathrm{g} \mathrm{g}^{-1}$.
TABLE IX

Results of Lanthanides and Th Obtained in Silliminite, Garnet, and Ilmenite Samples (values in $\mu \mathrm{g} \mathrm{g}^{-1}$ )

\begin{tabular}{lllllll}
\hline $\begin{array}{l}\text { Ele- } \\
\text { ment }\end{array}$ & $\begin{array}{c}\text { Silliminite } \\
\text { Present }\end{array}$ & \multicolumn{2}{c}{$\begin{array}{c}\text { Garnet } \\
\text { Method }\end{array}$} & IE & \multicolumn{3}{c}{$\begin{array}{c}\text { Ilmenite } \\
\text { Method }\end{array}$} & IE & $\begin{array}{c}\text { Present } \\
\text { Method }\end{array}$ & IE \\
\hline $\mathrm{La}$ & 10 & 9.2 & $110(2.2)$ & 105 & 26 & 25 \\
$\mathrm{Ce}$ & 22 & 21 & $155(2.5)$ & 150 & 41 & 40 \\
$\mathrm{Pr}$ & 2.1 & 2.0 & $25(4.6)$ & 24 & 2.5 & 2.3 \\
$\mathrm{Nd}$ & 8.0 & 8.6 & $105(3.5)$ & 107 & 22 & 21 \\
$\mathrm{Sm}$ & 2.1 & 2.3 & $27(4.0)$ & 28 & 3.9 & 4.0 \\
$\mathrm{Eu}$ & $<0.1$ & $<0.1$ & $0.45(1.6)$ & 0.50 & 0.38 & 0.40 \\
$\mathrm{Gd}$ & 2.0 & 2.1 & $36(2.8)$ & 34 & 2.7 & 2.8 \\
$\mathrm{~Tb}$ & $<1$ & $<1$ & $3.5(5.1)$ & 3.3 & $<1$ & $<1$ \\
$\mathrm{Dy}$ & 2.5 & 2.3 & $45(2.9)$ & 42 & 1.2 & 1.2 \\
$\mathrm{Ho}$ & $<1$ & $<1$ & $9.0(3.8)$ & 9.2 & $<1$ & $<1$ \\
$\mathrm{Er}$ & 2.5 & 2.5 & $26(4.8)$ & 27 & $<1$ & $<1$ \\
$\mathrm{Tm}$ & $<0.5$ & $<0.5$ & $3.8(4.9)$ & 3.5 & $<0.5$ & $<0.5$ \\
$\mathrm{Yb}$ & 2.7 & 2.7 & $25(2.1)$ & 24 & 0.7 & 0.7 \\
$\mathrm{Lu}$ & $<0.5$ & $<0.5$ & $3.8(1.6)$ & 3.9 & 0.1 & 0.1 \\
$\mathrm{Y}$ & 26 & 27 & $250(1.8)$ & 255 & 3.4 & 3.5 \\
$\mathrm{Th}$ & 13 & 14 & $95(2.9)$ & 97 & 90 & 86 \\
\hline $\mathrm{IE}$ & & & & & & \\
\hline
\end{tabular}

IE - Ion Exchange.

Values in parentheses are the \%RSD.

Chemical Composition of Garnet and Silliminite $\% \mathrm{SiO}_{2} \% \mathrm{TiO}_{2} \% \mathrm{Al}_{2} \mathrm{O}_{3} \% \mathrm{FeO} \% \mathrm{MnO} \% \mathrm{MgO} \% \mathrm{CaO} \% \mathrm{P}_{2} \mathrm{O}_{5}$ $\begin{array}{lllllllll}\text { Garnet } & 37.7 & 1.25 & 21.00 & 30.7 & 0.33 & 7.29 & 1.01 & 0.2 \\ \text { Silliminite } & 37.3 & 0.58 & 58.42 & 0.16 & <0.01 & 0.06 & 0.39 & 0.13\end{array}$ 
and acid hydrolysis (38) separation procedures. The data listed in Tables IX and XI show that the recovery was more than $95 \%$, and the method is in good agreement with the reported values.

\section{CONCLUSION}

The co-precipitative behavior of trace amounts of lanthanides and thorium as their oxalate in the presence of calcium as carrier at a different $\mathrm{pH}$ ( 1 to 4 ) was studied. It was investigated (a) how to overcome the possible loss of lanthanides and (b) to develop an easy and simple method for the separation of lanthanides and Th for the analysis of geological materials, certain environmental samples, industrial waste materials, and high salt content samples. By using around $300 \mathrm{mg}$ calcium as carrier during the oxalate precipitation and maintaining the $\mathrm{pH}$ at 1 , quantitative recovery of all of the lanthanides and Th at trace levels was achieved.

Studies were also conducted to understand the effect of calcium on the emission signal of individual lanthanides as well as the effect of forward power in the plasma. It was observed that the presence of calcium at $1 \mathrm{mg} \mathrm{mL}^{-1}$ or above in the aspirated solution suppresses the emission signal. Therefore, a second hydroxide precipitation separation of lanthanides and Th was carried out using $20 \mathrm{mg}$ stannic tin or $10 \mathrm{mg} \mathrm{Fe}$ (III) as carrier. The stannic tin was further removed as insoluble stannic acid by the nitric acid treatment.

The proposed method has a wide range of applications for different types of rocks, soils, bauxite, refractory minerals (such as garnet, silliminite, ilmenite, rutile, columbite-tantalite), and industrial waste materials (such as red mud and coal fly ash samples). The accuracy of the method was established by analyzing certain reference materials and the reproducibility
TABLE X

Recovery Study of Lanthanides and Th (in $\mu g$ amounts)

in Synthetic Matrix of Ilmenite, Rutile, and Columbite-Tantalite Type Minerals

\begin{tabular}{lcrrrr}
\hline $\begin{array}{c}\text { Ele- } \\
\text { ment }\end{array}$ & $\begin{array}{c}\text { Taken } \\
(\mu \mathrm{g})\end{array}$ & Ilmenite & \multicolumn{3}{c}{ Found $(\mu \mathrm{r})$} \\
\hline $\mathrm{La}$ & 75 & 72 & 72 & 73 & 72 \\
$\mathrm{Ce}$ & 150 & 147 & 156 & 154 & 152 \\
$\mathrm{Pr}$ & 75 & 75 & 77 & 75 & 75 \\
$\mathrm{Nd}$ & 150 & 148 & 152 & 152 & 149 \\
$\mathrm{Sm}$ & 90 & 89 & 92 & 92 & 91 \\
$\mathrm{Eu}$ & 15 & 14.9 & 14.9 & 14.6 & 15.1 \\
$\mathrm{Gd}$ & 60 & 57 & 57 & 59 & 59 \\
$\mathrm{~Tb}$ & 60 & 62 & 58 & 60 & 60 \\
$\mathrm{Dy}$ & 60 & 58 & 59 & 62 & 61 \\
$\mathrm{Ho}$ & 30 & 31 & 31 & 30 & 31 \\
$\mathrm{Er}$ & 60 & 63 & 61 & 61 & 59 \\
$\mathrm{Tm}$ & 30 & 29 & 29 & 30 & 31 \\
$\mathrm{Yb}$ & 7.5 & 7.4 & 7.1 & 7.7 & 7.6 \\
$\mathrm{Lu}$ & 15 & 14.2 & 13.9 & 14.1 & 14.3 \\
$\mathrm{Y}$ & 50 & 49 & 48 & 52 & 49 \\
$\mathrm{Th}$ & 100 & 96 & 97 & 96 & 98 \\
\hline $\mathrm{Comp}$ & & & & & \\
\hline
\end{tabular}

Composition of synthetic samples:

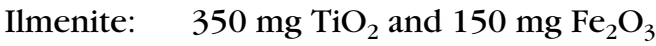

Rutile: $\quad 450 \mathrm{mg} \mathrm{TiO}$ and $50 \mathrm{mg} \mathrm{Fe} \mathrm{O}_{3}$

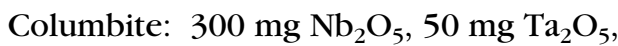

$50 \mathrm{mg}$ each $\mathrm{Fe}_{2} \mathrm{O}_{3}, \mathrm{MnO}_{2}$, and $\mathrm{TiO}_{2}$

Tantalite: $200 \mathrm{mg} \mathrm{Ta} \mathrm{Ta}_{5}, 150 \mathrm{mg} \mathrm{Nb}_{2} \mathrm{O}_{5}$, $50 \mathrm{mg}$ each $\mathrm{Fe}_{2} \mathrm{O}_{3}, \mathrm{MnO}_{2}$, and $\mathrm{TiO}_{2}$
TABLE XI

Results (in $\mu \mathrm{g} \mathrm{g}^{-1}$ ) of Lanthanides and Th in Natural Rutile and SRMs IGS-33 Columbite, and IGS-34 Tantalite Samples

\begin{tabular}{lllllll}
\hline $\begin{array}{l}\text { Ele- } \\
\text { ment }\end{array}$ & \multicolumn{2}{c}{$\begin{array}{c}\text { Natural } \\
\text { Rutile }\end{array}$} & \multicolumn{2}{c}{$\begin{array}{c}\text { SRM IGS-33 } \\
\text { Columbite }\end{array}$} & \multicolumn{2}{c}{$\begin{array}{c}\text { SRM IGS-14 } \\
\text { Tantalite }\end{array}$} \\
\hline \multicolumn{3}{c}{$\begin{array}{c}\text { Present } \\
\text { Method Exchange }\end{array}$} & $\begin{array}{c}\text { Ion } \\
\text { Method }\end{array}$ & $\begin{array}{l}\text { Present } \\
\text { Meported }\end{array}$ & $\begin{array}{l}\text { Present } \\
\text { Method }\end{array}$ & Reported \\
\hline La & 51 & 50 & 120 & 134 & 110 & 120 \\
$\mathrm{Ce}$ & 113 & 110 & 490 & 426 & 279 & 268 \\
$\mathrm{Pr}$ & 12 & 11 & 35 & 42 & 32 & 39 \\
$\mathrm{Nd}$ & 46 & 45 & 160 & 166 & 168 & 178 \\
$\mathrm{Sm}$ & 8.6 & 8.7 & 54 & 61 & 176 & 219 \\
$\mathrm{Eu}$ & $<0.10$ & $<0.10$ & 1.8 & 1.6 & 3.7 & 3.5 \\
$\mathrm{Gd}$ & 5.4 & 5.5 & 88 & 85 & 280 & 307 \\
$\mathrm{~Tb}$ & $<1$ & $<1$ & 22 & 25.4 & 65 & 72.5 \\
$\mathrm{Dy}$ & 5.0 & 5.1 & 185 & 195 & 275 & 293 \\
$\mathrm{Ho}$ & $<1$ & $<1$ & 42 & 43.6 & 30 & 28 \\
$\mathrm{Er}$ & 3.0 & 3.2 & 191 & 199 & 67 & 82 \\
$\mathrm{Tm}$ & $<0.5$ & $<0.5$ & 45 & 50 & 12 & 13 \\
$\mathrm{Yb}$ & 2.8 & 2.8 & 470 & 448 & 104 & 105 \\
$\mathrm{Lu}$ & 0.5 & 0.5 & 70 & 72 & 14 & 15 \\
$\mathrm{Y}$ & 33 & 32 & 1050 & 983 & 873 & 891 \\
$\mathrm{Th}$ & 58 & 60 & 850 & 942 & 1190 & 1205 \\
\hline
\end{tabular}


was characterized by replicate analysis (RSD of 2 to 6\%).

\section{ACKNOWLEDGMENT}

The author is thankful to Shri V.N. Dwivedi, Ex-In-Charge, Chemistry Laboratory, CR, AMD, Nagpur, India, for constant encouragement and valuable suggestions. The author is also grateful to the Regional Directors, Central Region and Southern Region, for providing the facilities, and to the Director, AMD, for granting permission to publish this work.

$\overline{\text { Received August 13, } 2011 .}$

\section{REFERENCES}

1. L.A. Haskin, in Rare Earth elements Geochemistry, Ed. P. Henderson, Elsevier, Amsterdam, The Netherlands, pp 115-148 (1984).

2. H. Wayne Nesbitt, Nature 279, 206 (1979).

3. C.K. Gupta and N. Krishnamurthy, Extractive Metallurgy of Rare Earths, CRC Press, Boca Raton, FL and New York, (USA), pp 11-20, (2005).

4. D.L. Nelson, H.S. Whittingham and T.F. George, Eds., in ACS Symposium Series, Vol. 351 (1987).

5. E. Elattar, W.E. Wallace and R.S. Craig, in The rare earths in modern science and technology, Vol.1, J.G. McCarthy and J.G. Rhyne, Eds., Plenum Press, NewYork, USA (1977).

6. T.P. Rao and V.M.N. Biju, Rev. Anal. Chem. 21, 233, (2002).

7. K.J.M. Kramer, H. Muntau, and P. Quevauviller, Trends Anal. Chem. 21, 762 (2002).

8. J.G. Sen Gupta, Talanta 23, 343 (1976).

9. J. G. Sen Gupta, Talanta 32, 1, (1985).

10. N. Bahramifar and Y. Yamini, Anal. Chim. Acta 540, 325 (2005).
11. R. Djingova and J. Ivanova, Talanta 57, 821 (2002).

12. P. Liang, Y. Liu and L. Guo, Spectrochim. Acta, 60B, 125 (2005).

13. C.H. Gonzaloz, A.J.Q. Cabezas and M.F. Diaz, Talanta 68, 47 (2005).

14. L. Qi, M.F. Zhou, J. Malpas and M. Sun, Geostand. Geonewslett. Res. 29, 131 (2005).

15. Bei Wen, Xiao-quan Shan and Shu-guang Xu, Analyst 124, 621 (1999).

16. F. Fujimori, T. Hayashi, K. Inagaki and H. Haraguchi, Fresenius J. Anal. Chem. 363, 277 (1999).

17. Shuzhen Zhang and Xiao-quan Shan, At. Spectrosc. 18, 80 (1997).

18. J.L. Todoli, L. Gras, V. Hernandis and J. Mora, J. Anal. At. Spectrom. 17, 142 (2002).

19. J.G. Crock, F.E. Lichte and T.R. Wildeman, Chem. Geol. 45, 149 (1984).

20. J.C. Farinas, H.P. Cabrera and M.T. Larrea, J. Anal. At. Spectrom. 10, 511 (1995).

21. J.G. Crock, F.E. Lichte, G.O. Riddle and C.L. Beech, Talanta 33, 601 (1986).

22. M.B. Shabani, T. Akagi and A. Masuda, Anal. Chem. 64, 737 (1992).

23. Dalibor Weiss, Tomas Paukert and Ivan Rubeska, J. Anal. At. Spectrom. 5, 371 (1990).

24. P.K. Srivastava and A.Premadas, J. Anal. At. Spectrom. 14, 1087 (1999).

25. I.M. Kolthaoff, Ed. Treatise on Analytical Chemistry, Part-II, Analytical Chemistry of Elements, Vol. 8, Interscience Publishers, John Wiley and Sons, New York, USA (1963).

26. D.S.R. Murthy, P.L. Mohanta and R. Radhamani, At. Spectrosc. 23, 65 (2002).

27. P. Roychowdhury, N.K. Roy, D.K. Das and A.K. Das, Talanta 36, 1183 (1989).

28. D.K. Das and P. Roychowdhury, At. Spectrosc. 18, 140 (1997).

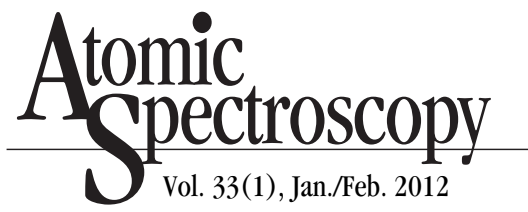

29. K. Iwasaki and H. Haraguchi, Anal. Chim. Acta 208, 163 (1988).

30. D.W. Zachmann, Anal. Chem. 60, 420 (1988)

31. M. Thompson and M.H. Ramsey, Analyst 110, 1413 (1985)

32. X. Romero, E. Pussel and J.M. Mermet, Spectrochim. Acta 52B, 495 (1997).

33. I.B. Brenner, M. Zischka, B. Maichin and G. Knapo, J. Anal. At. Spectrom. 13, 1257 (1998).

34. I.B. Brenner, J.M. Mermet, I. Segal and G.L. Long, Spectrochim. Acta 50B, 323 (1995).

35. I.B. Brenner, I. Segal, M. Mermet and J.M. Mermet, Spectrochim. Acta 50B, 333 (1995).

36. M. Hirade, Zon-Shongchen, K. Sugimoto and H. Kawaguchi, Anal. Chim. Acta 302, 103 (1995).

37. A. Premadas, At. Spectrosc. 24, 149 (2003).

38. K. Satyanarayana, At. Spectrosc. 17, 69 (1996).

39. A. Premadas, Bull. Chem. Soc. Japan 66, 2425 (1993). 